\title{
REFLEXÕES SOBRE AS ORIGENS DAS DESIGUALDADES DE GÊNERO: A TEORIA DA VALÊNCIA DIFERENCIAL DOS SEXOS DE FRANÇOISE HÉRITIER.
}

Nadia Veronique Jourda Kovaleski

nadia@utfpr.edu.br

Universidade Tecnologica Federal do Paraná, Ponta Grossa, Paraná, Brasil.

\section{Cintia de Souza Batista Tortato} cintiatortato@hotmail.com Instituto Federal do Paraná (IFPR) Paranaguá, Paraná, Brasil.

\author{
RESUMO
}

O objetivo desse estudo é de interrogar-se sobre a origem das desigualdades entre os homens e as mulheres. De fato, nas sociedades atuais as disparidades entre homens e mulheres são grandes. A antropóloga e etnóloga Françoise Héritier, feminista e humanista, especialista das populações africanas e particularmente dos sistemas da aliança e das ligações familiares, estudou as relações entre homens e mulheres nos primórdios da humanidade e emitiu a teoria da valência diferencial dos sexos. Nossa analise apoia-se nessa teoria para explicar as desigualdades entre os sexos. Trata-se de um estudo bibliográfico. Chega-se à conclusão que não é o sexo, mas a fecundidade das mulheres que representou a grande diferença entre os homens e as mulheres e que a opressão das mulheres provém justamente da apropriação desse privilégio pelos homens.
\end{abstract}

PALAVRAS-CHAVE: Gênero. Desigualdade de sexos. Estudos de gênero. 
INTRODUÇÃO

"Há um princípio bom que criou a ordem, a luz, o homem; e um princípio
mau que criou o acaso, as trevas, e a mulher, diz Pitágoras. As leis de Manu
definem-na como um ser vil que convém manter escravizado. O Levítico
assimila-a aos animais de carga que o patriarca possui. As leis de Sólon não
Ihe conferem nenhum direito. O código romano coloca-a sob tutela e
proclama-lhe a "imbecilidade". O direito canônico considera-a "a porta do
Diabo". O Corão trata-a com o mais absoluto desprezo".
Simone de Beauvoir

Ao iniciar estudos de gênero o primeiro grande questionamento que surge é a respeito do por que das disparidades entre os sexos. Hoje, nos países ocidentais mesmo se a desigualdade tende a diminuir, ainda existem nichos exclusivamente masculinos: na política, na religião, nas empresas.

Por quais razões a humanidade desenvolveu sistemas de pensamento valorizando o masculino e desvalorizando o feminino? De fato, sustentar como Simone de Beauvoir (2000) que as servidões da reprodução fazem que até hoje a mulher esteja restrita à esfera privada é uma explicação válida, mas que não sustenta a constante desvalorização do feminino nem a opressão das mulheres. Segundo Engels (1972), a opressão das mulheres pelos homens teria surgido na Idade do Bronze com a propriedade privada. Antes disso, as sociedades humanas teriam sido totalmente igualitárias. Todo o conhecimento antropológico atual refuta essa tese como também de sociedades matriarcais. (HÉRITIER, 1996)

A corrente materialista feminista dos anos 70 , com a sua maior expoente, Christine Delphy (2009), introduziu a ideia de patriarcado definido como uma estrutura social hierarquizante e desigual onde a classe dos homens apropria-se da classe das mulheres graças a mecanismos sociais: exploração do trabalho reprodutivo gratuito, instituição do casamento, da família, do privado. No entanto, podemos nos perguntar a razão primordial que levou a tal apropriação.

Nos seus livros Masculino/Feminino: o pensamento da diferença $e$ Masculino/feminino II, Dissolver a hierarquia, a antropóloga Françoise Héritier, demonstra que existe um alfabeto simbólico universal (HÉRITIER, 1996) ancorado numa mesma natureza biológica. Cada sociedade humana decompõe as características do mundo natural em "associações sintagmáticas que variam segundo as sociedades" (HÉRITIER, 1996, p.22). Isto é, as divisões sexuais do trabalho tal qual as conhecemos nas sociedades ocidentais estão longe de serem fenômenos universais. No entanto, para essa pesquisadora existe um domínio onde as sociedades humanas elaboraram uma só tradução: é o que ela chama de "valência diferencial dos sexos" (HÉRITIER, 1996, p. 23). Héritier ao introduzir a categoria gênero nos seus estudos antropológicos conseguiu ir muito além das explicações de Beauvoir $(1981,2000)$ com veremos a seguir.

\section{A VALÊNCIA DIFERENCIAL DOS SEXOS}

A "valência diferencial dos sexos" (HERITIER, 2002, p. 91-92) pode ser definida como: 
O lugar diferente que é atribuído universalmente aos dois sexos numa tabela de valores e assinala a dominância do princípio masculino sobre o princípio feminino. A relação homem/mulher é construída sobre o mesmo modelo que a relação pais/filhos, que a relação irmão mais velho/irmão mais novo e, mais em geral, que a relação anterior/posterior, significando a anterioridade e a superioridade. Esta série de equivalência é universalmente aceita. Que eu saiba, não há nenhuma sociedade, mesmo matrilinear, que atue invertendo estas relações ou simplesmente negando a sua existência.

A valência diferencial dos sexos encontra-se no sistema binário de oposições que nos serve para pensar: quente/frio, alto/baixo, duro/mole, criação/repetição. Todas as línguas recorrem a essas oposições binárias que deveriam ser neutras, mas são hierarquizadas e são relacionadas a um sexo: o masculino, sempre valorizado e o feminino, desvalorizado.

Conforme (HÉRITIER, 1996, 2002) essa categorização remonta às origens da humanidade sendo a classificação uma das primeiras operações mentais dos quais se origina o pensamento. A reflexão dos homens só pode recair senão sobre o que the era dado observar de mais perto: o corpo e o meio ambiente. 0 corpo humano lugar de constantes, mas, também de diferenças entre as quais a sexual é a principal. De fato os homens e as mulheres têm corpos diferentes e funções diferentes na reprodução. Isso nos conduz a um dos themata arcaico (HÉRITIER, 1996) de todo pensamento antigo, moderno, científico: o idêntico e o diferente.

HÉRITER (1996) argumenta que a relação idêntico/diferente é a base dos sistemas que opõem dois a dois valores concretos e abstratos: calor/frio, seco/úmido, alto/baixo, inferior/superior, claro/escuro. Esses valores encontramse também na classificação do feminino e do masculino. Por exemplo, para Aristóteles, a mulher é úmida e fria ${ }^{1}$ e o homem quente e seco (SISSA, 1990). A partir desse momento é interessante se perguntar por qual passe de mágica as categorias associadas ao masculino são sempre consideradas superiores àquelas associadas ao feminino, sendo que isso, não depende das categorias em si ${ }^{2}$.

Para responder, Héritier $(1996,2002)$ levanta a hipótese que a valência diferencial dos sexos provém menos de um handicap do lado feminino que da expressão de uma vontade de controle da reprodução por parte dos homens.

\section{O PRIVILÉGIO DAS MULHERES}

Nessa relação idêntico/diferente um grande questionamento deve ter surgido nas primeiras sociedades humanas: como as mulheres conseguem procriar um ser diferente delas? $\mathrm{O}$ fato de que uma mulher pudesse gerar outra mulher pode parecer natural, mas como ela consegue gerar um homem? (HÉRITIER, 1996, 2002).

Esse questionamento deixou rastros na mitologia, assim pode se entender o mito popular africano que explica que no início os homens e as mulheres viviam separados se reproduzindo sozinhos. Até que cometerem um erro e foram condenados pela divindade suprema a viver juntos. Os homens mais culpados foram mais punidos e assim perderam o direito de se reproduzir sozinhos: 
deveriam passar pelos corpos das mulheres (HÉRITIER, 1996, 2002). Como vemos esse mito explica como as mulheres procriam meninos.

Pode-se emitir a hipótese que a partir dessa constatação, em todas as sociedades humanas estudadas até hoje, instituiu-se sistemas de parentesco, crenças a respeito da fecundidade, da procriação, da esterilidade, instituições como o casamento, divisões sexuais no trabalho, que visam a controlar e mesmo a tirar esse privilégio das mulheres de conceber filhos do sexo masculino (HÉRITIER, 1996, 2002). A autora argumenta: “Assim, não é o sexo, mas a fecundidade que faz a diferença real entre o masculino e o feminino, e a dominação masculina (...) é o controle, a apropriação da fecundidade da mulher, enquanto for fecunda" (HÉRITIER, 1996, p. 218).

Convém neste momento justificar de como essa hipótese entre outras nos pareceu mais convincente.

De fato, ao analisar historicamente as relações de gênero nas sociedades ocidentais, a opressão das mulheres é justificada nos discursos filosóficos, literários, políticos, religiosos, medicinais, pela própria natureza da mulher. A mulher é qualificada como sendo uma criatura irracional, sem lógica, curiosa, indiscreta, tagarela, incapaz de guardar um segredo, de pouca criatividade nas atividades intelectuais, medrosa, escrava do seu corpo, pouco apta a dominar e a controlar suas paixões, inconsequente, histérica, traidora, ciumenta, indisciplinada, impudica, perversa... Eva, Dalila, Pandora.

Ela é ainda qualificada num outro corpo de discurso aparentemente menos negativo, frágil, doce, emotiva, procurando a paz, a estabilidade, o conforto do lar, fugindo das responsabilidades, incapaz de tomar uma decisão, crédula, intuitiva, sensível, tenra, precisando pela sua natureza de ser submetida, dirigida e controlada por um homem.

As mulheres não são nenhuma minoria, mas a metade da humanidade que reproduz justamente a outra metade, então, qual seria o propósito de ter construído ao longo dos milênios essa natureza feminina senão para possuir os argumentos que justificam controlá-la nos seus mais íntimos movimentos? O fato que os homens têm que usar o corpo das mulheres para se reproduzirem, não justificaria tal controle? Héritier (2011, p. 31) argumenta: "É preciso convencer as mulheres da sua inferioridade, lembrar-Ihes que não são livres porque fariam mau uso dessa liberdade; elas não têm acesso ao saber por falta de inteligência e de julgamento; não exercem o poder por que são frívolas e facilmente histéricas".

Acreditamos, como a antropóloga Françoise Heritier, que a reprodução, isto é, o fato de poder gerar meninas e meninos representa um enorme privilégio pelo qual as mulheres pagam um preço exorbitante, o preço da sua liberdade.

É interessante agora tentar desvelar por quais mecanismos os homens apropriaram-se desse privilégio. 


\section{A APROPRIAÇÃO DO PRIVILÉGIO}

\section{Fertilidade versus reprodução}

A reprodução humana e a fecundidade feminina são muitas vezes evocadas para justificar o estado de subordinação das mulheres e as desigualdades de gênero. A posição subordinada da mulher seria devida a incômodos biológicos naturais (BEAUVOIR, 2000). A literatura etnológica, antropológica, filosófica fala de uma função reprodutiva das mulheres que parece constante no espaço e no tempo desde milênios. As gestações parecem ser naturais como as estações do ano. A realidade é outra e pode se argumentar que existe um no man's land ${ }^{3}$ (TABET, 1998) entre o potencial biológico e a procriação.

Tabet (1998, p. 85-86) indaga:

O caráter social da atividade reprodutiva exige que se interrogue sobre o seu estatuto como atividade, sobre a sua classificação entre as atividades humanas: é trabalho? Pode se aplicar à reprodução as noções de trabalho alienado? De exploração, de apropriação-expropriação do produto?

Conforme Short (1978) e Leridon (1973) a espécie humana é relativamente infértil, as possibilidades de conceber só com um coito são limitadas. Existem também características específicas da sexualidade humana:

- a pulsão sexual das mulheres não é ligada à procriação, isto é, não há sincronia entre a ovulação e a pulsão sexual, por isso, copulação e fecundação podem acontecer na ausência de desejo sexual das mulheres;

- mesmo com bom conhecimento fisiológico é difícil estabelecer o momento onde a concepção será possível devido à variabilidade da ovulação de cada mulher;

- a sexualidade não é sempre ligada a comportamentos bio- reprodutivos, mas pode também ser ligada a comportamentos socioafetivos.

- a diversidade sexual é uma característica da sexualidade humana, isto é, a heterossexualidade convive com outras possibilidades de orientação sexual.

Se as mulheres não são biologicamente coagidas à reprodução, como acontece de fato essa reprodução?

Ao longo dos milênios instalaram-se sistemas complexos de pressão social, física, ideológica que vão coagir as mulheres à reprodução. Tabet (1998) vai tratar de vários mecanismos em diferentes sociedades que vão coagir as mulheres a ter relações sexuais. Beach ${ }^{4}(1974$, apud TABET, 1998) argumenta que na reprodução humana não é exato definir as mulheres como sempre receptivas, mas é melhor dizer que são sempre copuláveis ${ }^{5}$. O casamento é o operador de base entre não ser sempre receptivas, mas sempre copuláveis, porque além de ser a instituição que estabelece a aliança pela troca de mulheres, que liga homens e mulheres na divisão sexual do trabalho, que legitima os filhos, ele é, também, o lugar que parece garantir o máximo de probabilidade de fecundidade: "Em geral, pelo casamento, é assegurado uma permanência de exposição ao coito, isto é, uma permanência de exposição ao risco de gravidez" (TABET, 1998, p. 91). 
Pode-se observar como o casamento é sintomático na coação a procriar, quando se analisa o estigma em torno da mãe solteira que existe em quase todas as sociedades humanas. Por exemplo, no início da América puritana, a mulher julgada por fornicação - atos sexuais entre pessoas não casadas - era multada e espancada em público. (YALOW, 2002)

A primeira obrigação de uma esposa sempre foi de procriar e, em muitas partes do mundo atual, de procriar um filho homem.

\section{Quem fabrica os filhos são os homens}

Em diversas sociedades ditas primitivas, no discurso filosófico de Aristóteles que teve uma grande influência nas sociedades ocidentais, no discurso medicinal dos séculos XIX e XX são os homens que detém a aptidão, no ato da procriação, de fazer meninos.

Conforme Héritier $(1996,2002)$ a busca de uma verdade universal apoia-se no estudo das sociedades consideradas mais primitivas, isto é, as sociedades de caçadores-coletores. O critério principal para estabelecer uma ligação com os nossos ancestrais é o meio de subsistência. Quando se trata de caçadorescoletores que não plantam, não criam animais e não conhecem a metalurgia considera-se que perpetuam um modo de vida que data do paleolítico. Há atualmente em torno de 30 sociedades de caçadores- coletores. Claro, que tiverem também a sua história e evolução por isso fala-se de semelhança e não de identidade. Elas não oferecem uma visão uniforme das relações de gênero que poderia ser a sobrevivência de um modelo arcaico, mas todas elas manifestam a existência de uma supremacia masculina.

Na África, Heritier $(1996,2002)$ estudou desde os anos sessenta o povo Samo. Neste povo a categoria central binária é o quente e o frio, todos os elementos, sejam eles naturais ou artificiais, dependem dela. Ao frio está associado o úmido e ao quente o seco. Assim: "A aldeia é fria e a floresta quente, o solo é quente, a lua é fria, o homem quente e a mulher fria, a terra é masculina e quente, a chuva é fria, o ato sexual é quente, mas o casamento é frio" (HERITIER, 1996, p. 124). Para os Samo toda mulher fecunda possui uma matriz onde se desenvolve e "cozinha" a criança. No centro da matriz uma pequena bola de sangue com um orifício rola perpetuamente sobre si mesma. No momento das relações sexuais a bola cessa de rolar e quando seu orifício é dirigido para a vagina a concepção acontece (HÉRITIER, 1996).

Quando uma mulher está grávida o desenvolvimento da criança vai depender do pai. De fato, o esperma do homem dentro do corpo da mulher se transforma em sangue e penetra na criança. Durante os sete primeiros meses de gravidez o bom desenvolvimento da criança dependerá da frequência das relações sexuais (HÉRITIER, 1996, 2002). No povo Samo é impossível para uma mulher levar a cabo uma gravidez sozinha, porque a criança precisa do esperma/sangue do pai para se desenvolver. Para o povo trobiandense, estudado por Malinowski (1930) a fecundação acontece quando um espírito ancestral entra na mulher. O homem vai dar forma a esse espírito e a mulher alimentá-lo.

Essas concepções vão de encontro ao pensamento grego de Aristóteles, Hipócrates, Anaximandro, onde as categorias centrais são também o frio/úmido e quente/seco associadas, respectivamente, ao feminino e ao masculino. Para 
Aristóteles, na concepção o homem possui o pneuma (esperma) - ar quente da vida - e a mulher, a matéria. O pneuma vai dar forma à matéria:

Visto que o esperma é um resíduo, e está animado de um movimento idêntico àquele pelo qual o corpo cresce à medida que nele se distribuem as parcelas de alimentos definitivamente elaborados (o sangue), quando penetra no útero coagula e põe em movimento o resíduo da fêmea, imprimindo-lhe o movimento de que ele próprio está animado. (Aristóteles, apud Sissa, 1990, p. 108).

O macho para Aristóteles é aquele capaz de realizar, pela força do seu calor, a cocção do sangue, e de transformá-lo em esperma, sendo assim dotado de um calor maior que a fêmea. É por ser fria que a fêmea tem mais sangue e o perde: senão, faria dele esperma (HÉRITER, 1996, 2002; SISSA, 1990).

Aristóteles vai além quando formula que quando o princípio masculino não domina, mostra-se inferior às suas tarefas, nascerá uma menina. Assim, justifica ele, progenitores jovens e velhos dão mais vezes origem a nascimento de menina: "Nos primeiros, o calor ainda não é perfeito, nos outros, falta o calor" (ARISTÓTELES ${ }^{6}$, apud HÉRITIER, 1996, p.182).

Sob a cobertura da ciência objetiva, moderna, racional dos séculos XIX e XX os discursos são monotonamente os mesmos. Assim, o médico Julien Virey da Academia Real de Medicina da França escreve em 1825: "É certo que o esperma masculino impregna a organização da mulher, que ele acende todas as suas funções, que ele as aquece (...). Sem dúvida, a complexão mole e úmida das moças as torna eminentemente frágeis e delicadas [...] (VIREY, 1825, p. 85-86). Para Virey (1825) as moças que tardam a casar podem sofrer de histeria, de ninfomania, de neurose e de epilepsia, e as solteiras sofrerão continuamente devido a: doenças porque "seus órgãos não preencheram as funções às quais a natureza os submeteu[...] (VIREY, 1825, p.118)

Quanto à geração de menina ou menino o raciocínio do pensamento de Virey encontra aquele de Aristóteles. Assim, para ele, o casamento monógamo é melhor que o polígamo:

"Um homem entregue a várias mulheres se enfraquece pelos gozos múltiplos, enquanto a esposa que só possui, para assim dizer, um quarto ou um terço de homem, deve dominar no ato de reprodução. O resultado é que ela forneça mais de sua organização na propagação e produz mais fêmeas que machos (...) os machos são menos viris, menos ardentes, quando nascem de pais sobrecarregados de funções genitais e a raça continuará a degenerar (VIREY,1825 p. 147-148).

O médico vai mais longe ainda quando diz que a monogamia dos europeus permitiu avanços consideráveis, porque os machos dominam na geração (VIREY, 1825). Para esse médico a união perfeita entre os dois sexos é quando:

(...) a mulher é mais fêmea e o homem mais viril; é quando um macho moreno, peludo, seco, quente e impetuoso achou o outro sexo delicado, úmido, liso, branco, tímido, pudico. Um tem que dar e o outro é constituído para receber; o primeiro por essa razão deve ter um princípio de superabundância, de força, de generosidade, de liberalidade que aspira a se espalhar; o segundo, ao contrário, sendo constituído em menos deve, pela sua timidez, tender a recolher, a absorver mais do outro para estabelecer a igualdade(...), (VIREY, 1825, p. 195) [Tradução nossa]. 
A passividade/virilidade da mulher e do homem faz parte desses "sistemas categóricos de oposição" (HÉRITIER, 1996, p. 20) que se reencontram em diversos estágios da descrição da vida humana. Por exemplo, até os anos 80 , nos manuais sobre concepção, o esperma era descrito com ativo, corajoso, enfrentando todos os perigos e o óvulo era descrito como passivo, vagando inconscientemente nas trompas de Falópio, esperando ser despertado (SCHIEBINGER, 2001). Se as mulheres têm filhos não é da sua própria iniciativa: é do homem que provém o necessário para a fabricação dos filhos.

\section{De onde vem o esperma?}

A humanidade deu diversas respostas. A comida pode se transformar em semente, Deus ou alguns espíritos podem dar a semente, ou então provém de uma dotação inicial e a ajuda de alimentos especiais provocam a transformação. Mas, onde está armazenada essa semente? Segundo Héritier (2002) o mundo ocidental herdou do seguinte modelo explicativo: a semente é concentrada nos ossos e é armazenada na cabeça. No momento da relação sexual, ela desce ao longo da coluna "numa lenta defluxão que se torna brutal no momento do ato sexual e esvazia então o homem da sua substância", (HERITIER, 2002, p. 29). O corpo das mulheres não fabrica sementes, as suas cabeças estão vazias.

No pensamento grego, cuja influência é forte no Ocidente, o corpo das mulheres é caracterizado por esse vazio, os órgãos estão soltos no corpo e nas jovens virgens, o útero pode até se alojar no cérebro (HÉRITIER, 2002).

\section{Os sistemas de parentesco}

O sistema de parentesco (conjunto de regras que governa a filiação, a residência e a aliança) é definido pelas relações que unem os homens e as mulheres entre si por ligações fundadas na consanguinidade e a afinidade. Essa definição, segundo Héritier $(1996,2002)$, que tenta se moldar de mais perto à realidade biológica, é longe de ser correta.

De fato, ao analisar as diferentes sociedades humanas existentes no planeta atualmente, os (as) antropólogos(as) chegaram à conclusão que a filiação e a consanguinidade são sociais.

Françoise Héritier (1999, p. 29) nos dá dois exemplos dessa conclusão. Na sociedade Samo do Burkina Faso, a menina é dada em casamento desde seu nascimento. No entanto na adolescência, após a puberdade, ela pode escolher um amante com o qual viverá até o nascimento do primeiro filho ou no máximo por três anos se não tiver filho. O recém-nascido será considerado filho do marido legítimo. Na sociedade Samo, mesmo sendo de ideologia patrilinear, a grande maioria dos primogênitos não são filhos biológicos do pai.

Outro exemplo é das sociedades que possuem um sistema dualista de metades exogâmicas, isto é, essas sociedades são divididas em dois e o cônjuge deve ser escolhido sempre na outra metade. Nessas sociedades, o casamento mais próximo que pode acontecer é entre primos cruzados bilaterais, por exemplo, um homem vai casar com a filha da irmã do pai e do irmão da mãe. Nesse tipo de sociedade os primos cruzados não se consideram consanguíneos, mas aliados. No entanto, os primos paralelos pertencentes à mesma metade são considerados consanguíneos e não podem se casar entre si. 
Heritier (1996, p. 50) argumenta: “A reprodução dos homens é um instrumento da reprodução da ordem social. Ela entra na reprodução simbólica da ordem social a ponto de podermos dizer que um sistema de parentesco não existe senão na consciência dos homens e que não é mais que um sistema arbitrário de representação".

Hoje, os(as) antropólogos(as) classificaram seis grandes sistemas-tipos de parentesco diferentes: omaha, crow, esquimó, havaiano, sudanês, iroquês. Nesses sistemas, a filiação pode ser bilateral ou cognata (somos aparentados da mesma maneira ao pai e a mãe), unilineares ou bilineares (somos aparentados ao pai ou à mãe somente).

Após ter estudado profundamente todos os sistemas de parentesco, Héritier (1996) chega a uma conclusão primordial para o nosso propósito, isto é a apropriação do privilégio das mulheres. Conforme essa pesquisadora, dentro da grande diversidade de sistema de parentesco existe um fato invariável em todas as sociedades:

Não encontramos em nenhum sistema do mundo uma relação mulher/homem ou caçula /primogênito - em que o primeiro dos termos esteja em posição dominante - que equivalha a uma relação pai/filho. Não encontramos nenhum sistema-tipo de parentesco que, na sua lógica interna, no pormenor das suas regras de geração, das suas derivações, desembocando no que se pode considerar uma relação que vai das mulheres aos homens, das irmãs aos irmãos, seja traduzível numa relação em que as mulheres seriam mais velhas e em que pertenceriam estruturalmente à geração superior. As ausências que notamos só se explicam assim: essa relação de desigualdade, sem fundamento biológico, prova que todo o sistema de parentesco é uma manipulação simbólica do real, uma lógica do social (HÈRETIER, 1996, p. 63).

A fecundidade das mulheres é vital para a sobrevivência de qualquer sociedade humana. Assim pode se explicar as leis de proibição do incesto e as leis de exogamia vigentes em quase todas as sociedades. Uma sociedade que recorreria unicamente ao incesto para se reproduzir seria levada ao desaparecimento porque a união do irmão com a irmã, por exemplo, só dá uma descendência em lugar de duas. Héritier comenta:

“O parentesco é a matriz geral das relações sociais. [...] a instituição primária que abre a solidariedade entre os grupos é o casamento. [...] a troca de mulheres entre os grupos é a troca de vida, uma vez que as mulheres dão os filhos e o seu poder de fecundidade a outros grupos além dos que lhes são próximos" (HÉRITIER, 1996, p. 220).

Como podemos ver neste ponto, Héritier $(1996,2002)$ vai além do pensamento de Simone de Beauvoir nos seu livro o Segundo Sexo. De fato, para Beauvoir (2000) a situação de opressão na qual é mantida a mulher provém dos efeitos fisiológicos e sociais da maternidade. Enquanto o homem caça, vai à guerra, conquista território, adquire tecnologia, a mulher permanece na imanência:

"Os trabalhos domésticos a que está voltada, porque só eles são conciliáveis com os encargos da maternidade, encerram-na na repetição e na imanência; reproduzem-se dia após dia sob uma forma idêntica que se perpetua quase sem modificação através dos séculos; não produzem nada de novo" (BEAUVOIR, 2000, p. 83). 
Na verdade, para Beauvoir, quem detém o privilégio são os homens. No entanto, é interessante notar que no seu livro, ela percebeu a hipótese de Héritier, mas sem explorá-la. Por exemplo, ela comenta (2000, p. 103): “Entre os árabes havia infanticídio em massa: mal nasciam, eram as meninas jogadas em fossos. Aceitar a criança de sexo feminino era um ato de livre generosidade por parte do pai (...)".

A teoria de Françoise Héritier aprofunda também o raciocínio de Levi-Straus (de quem foi aluna) porque mostra que no momento, ou, segundo esse autor, constituem-se os fundamentos do social, isto é, a proibição do incesto, a exogamia e a divisão sexual do trabalho, a valência diferencial dos sexos já existe. Levi-Strauss (1968) apresenta a proibição do incesto como uma renúncia pelos homens a usarem sexualmente para fins reprodutivos, as suas filhas e as suas irmãs. Elas seriam usadas para criar alianças com os outros grupos ao serem dadas em casamento. Isso permitiria também economizar vidas de guerreiros que não precisariam mais sair em incursões predadoras quando faltavam mulheres no seu grupo. Mas, argumenta Héritier (2002), para que os homens trocassem entre eles as mulheres do seu grupo era preciso que a valência diferencial dos sexos estivesse presente, senão as trocas funcionariam nos dois sentidos e para os dois sexos em quantidade igual.

O fato que o nascimento de uma menina ou de um menino nunca é neutro demonstra que os mecanismos que instalam ideologicamente e valorizam o masculino como transcendência não derivam unicamente da natureza que mutila as mulheres (maternidades), mas procedem de uma extorsão. Como explicar, então, a dureza da relação de sujeição e de apropriação em que as mulheres foram mantidas até nossos dias e ainda o são em muitos países? Sujeição que "se adequa ao respeito atribuído aos valores de fecundidade e de maternidade nas relações do casamento". (HÉRITIER, 2002, p. 85)

Assim pode-se explicar que atualmente, na Índia, 100.000 mil fetos do sexo feminino são eliminados por aborto a cada ano. Na China estudos mostram que a forma de desigualdade entre os sexos mais ressentida pela maioria das mulheres é a discriminação quando não conseguem ter um filho homem. (WARD et al, 2007).

\section{CONSIDERAÇÕES FINAIS}

A desigualdade não é um fato da natureza. Ela nasceu da observação de fatos biológicos, nos primeiros tempos da humanidade, que criaram representações mentais. Apesar de arcaicos e pouco percebidas, essas representações ainda são presentes em todas as sociedades. As mulheres são vistas na maioria das sociedades humanas como recurso para os homens se reproduzirem.

Hoje, no mundo ocidental, graças a grande revolução que aconteceu no século XX no destino da humanidade, isto é, a contracepção, o ventre das mulheres pode escapar ao controle dos homens. O seu corpo the pertence e a decisão de ter ou não filhos também. Mas como é pequeno o território dessas mulheres livres! Em muitas regiões do mundo, mas também perto de nós, entre nós, homens continuam a encarcerar mulheres na ignorância e submissão para controlar ainda e sempre, seu privilegio de procriar. Hoje em dia, mulheres 
sofrem violências ou são mortas porque homens colocam a sua honra no corpo das suas filhas, irmãs, esposas ou as consideram como parte de suas propriedades. E nossas sociedades desenvolvidas não são um abrigo a um retorno para trás. Não podemos esquecer que a liberdade das mulheres é recente e frágil e que elas mesmas devem tomar o seu destino nas próprias mãos e defender dia após dia seus direitos, inventar dia após dia um mundo misto onde sejam simplesmente seres humanos em toda sua integridade. 


\title{
REFLECTIONS ON THE ORIGINS OF GENDER INEQUALITY: THE THEORY OF VALENCE DIFFERENTIAL OF THE SEXES FROM FRANÇOISE HÉRITIER
}

\begin{abstract}
The objective of this study is to inquire into the origin of the inequalities between men and women. Indeed, in contemporary societies disparities between men and women are great. The ethnologist and anthropologist Françoise Héritier, feminist and humanist, specialist in African populations and particularly the systems of alliance and family connections, studied the relationships between men and women in the early days of humanity and have issued the theory of differential valence of the sexes. Our analysis is based on this theory to explain gender inequalities. This is a bibliographic study. Comes to the conclusion that it is not sex, but the fertility of women who represented the big difference between men and women and the oppression of women comes precisely from the appropriation of this privilege by men.
\end{abstract}

KEYWORDS: Gender. Gender inequalities. Gender studies. 
1 Essa classificação parte de uma observação concreta feita pelas primeiras sociedades humanas. Quando se mata um animal ele sangra e quando perdeu seu sangue torna-se frio, duro. Então a vida é mobilidade e calor e a morte imobilidade e frieza. Porque o homem é quente e seco? Porque não perde seu sangue. A mulher é fria e úmida porque perde regularmente seu sangue pelas menstruações sem poder fazer nada contra isso (HÉRITIER, 2011).

2 Por exemplo, no Ocidente a categoria "ativo(a)" é valorizada e associada ao masculino enquanto que "passivo(a)" é menos apreciada e associada ao feminino. Na Índia é o contrário: a passividade é valorizada e associada ao masculino e a atividade é desvalorizada e associada ao feminino (HÉRITIER, 2011).

3 No sentido onde na literatura etnológica e antropológica fala-se de aliança, casamento, troca de mulher, reprodução, mas raramente do exercício social da sexualidade, isto é, a exposição ao risco de gravidez das mulheres. (TABET, 1998).

4 BEACH, F.A. Human sexuality and evolution. New York: Plenum, 1974.

5 Nota-se a teorização implícita do estupro nessa definição.

${ }^{6}$ Aristóteles, De la génération des animaux, Paris, Les Belles Lettres, 1961

\section{REFERÊNCIAS}

BEAUVOIR, Simone de. O Segundo Sexo I: Fatos e Mitos. Rio de Janeiro: Nova Fronteira, 2000.

BEAUVOIR, Simone de. O Segundo Sexo II: A experiência vivida. Rio de Janeiro: Nova Fronteira, 1981.

DELPHY, Christine. L'ennemi principal I : économie politique du patriarcat. 2.edition . Paris : Sillepse, 2009.

DELPHY, Christine. L'ennemi principal II : penser le genre. 2. Edition. Paris: Sillepse, 2009.

ENGELS, Friederich. Les origines de la famille, de la propriété privée et de l'Etat. Paris: Editions Sociales, 1972.

HÉRITIER, Françoise. Masculino, feminino: o pensamento da diferença. Lisboa: Instituto Piager, 1996.

HÉRITIER, Françoise. Masculino, feminino: dissolver a hierarquia. Lisboa : 
HÉRITIER, Françoise et al. La plus belle histoire des femmes. Paris: Éditions du Seuil, 2011.

LERIDON, H. Aspects biométriques de la fécondité humaine. Paris: PUF, 1973.

MALINOWSKI, Bronislaw. La vie sexuelle des sauvages du Nord-Ouest de la Mélanésie : Description ethnographique des démarches amoureuses, du mariage et de la vie de famille des indégènes des îles Trobriand (NouvelleGuinée). $1930 . \quad$ Disponível em: $<$ http://classiques.uqac.ca/classiques/malinowsli/vie sexuelle/vie sexuelle.html >. Acesso o 20 de março de 2011.

SCHIEBINGER, Londa. O feminismo mudou a ciência? Bauru, SP: EDUSC, 2001.

SHORT, R. V. L'évolution de la reproduction humaine. Paris: Fayard, 1978.

SISSA, Giula. Filosofias do gênero: Platão, Aristóteles e a diferença dos sexos. In: PERROT Michelle; DUBY George (orgs). História das mulheres: A Antiguidade, v.1. Porto: Edições Afrontamento, 1990.

TABET, Paola. La construction social de l'inégalité des sexes. Paris: L'Harmattan, 1998.

VIREY, JULIEN. De la femme sous ses rapports physiologique, moral et littéraire. Paris : Imprimerie de Lachevardière fils, 1825. Disponível em $<$ http://books.google.fr/books?id=AhhKAAAAMAAJ\&printsec=frontcover\&dq=juli en+virey\&source=b|\&ots=WeedSCcGRu\&sig=7qzGCWEvboSDGMDbhSg>. Acesso em 28 de março 2011.

WARD, . Corps meurtris, rêves brisés : la violence à l'égard des femmes mise à jour. Malta: Progress Press Co Ltd, 2007. Disponível em: www.genreenaction.net/spip.php?article7144. Acesso em 18 de novembro 2010.

YALOW, Marilyn. A história da esposa: da Virgem Maria a Madonna, o papel da mulher casada dos tempos bíblicos até hoje. Rio de Janeiro: Ediouro, 2002. 
Recebido: 25 de junho de 2013.

Aprovado: 06 de julho de 2016.

Como citar:

KOVALESKI, N. V. J.; TORTATO, C. S. B.. Reflexões sobre as origens das desigualdades de gênero: a teoria da valência diferencial dos sexos de Françoise Héritier. Cad. Gên. Tecnol., Curitiba, v. 9, n. 34, p. 58-71, jul./dez. 2016.

Correspondência:

Cintia de Souza Batista Tortato

Rua Câmara Júnior, 1463, casa 2, Jardim das Américas, Curitiba, Paraná. CEP: 81540-000.

Direito autoral: Este artigo está licenciado sob os termos da Licença Creative Commons Atribuição 4.0 Internacional.

(c) (i) 